\title{
Blood Component Separation Service: A New Experience in an Institution
}

\author{
Santosh Upadhyaya Kafle, ${ }^{1}$ Gaurav Kattel, ${ }^{2}$ Tanchona Nembang, ${ }^{3}$ Smriti Karki ${ }^{3}$
}

'Department of Pathology, Birat Medical College and Teaching Hospital, Morang, Nepal, ${ }^{2}$ Grande International Hospital and Research Centre, Kathmandu, Nepal, ${ }^{3}$ Department of Pathology, B. P Koirala Institute of Health Sciences, Dharan, Nepal.

Introduction: Blood component separation facility began dispatching its blood component units from $21^{\text {st }}$ April 2013 at the new blood component separation service complex at B.P. Koirala Institute of Health Sciences. With the supply of blood components being finite and with the added recognition of a high rate of inappropriate use of blood component services around the world, there is a need to monitor and regulate these services. Our study was conducted to identify blood component utilization pattern in institute and to know about different blood components demand for future preparedness.

Methods: This retrospective study was conducted at B.P. Koirala Institue of Helath Sciences, Dharan, Nepal for blood component dispatched from 21 ${ }^{\text {st }}$ April, 2013- $12^{\text {th }}$ February, 2014. Blood components requisitions from all clinical department were reviewed regarding the specific component requested, blood group and socio-demographic profile.

Results: Among 3054 transfusion units dispatched, 1552 were males, 1498 females and 4 unspecified. Likewise, 1722 were pack cell volume, 808 platelet rich plasma, 523 fresh frozen plasma and 1 cryoprecipitate disptached respectively with majority of A positive blood group demanded from Neonatal and Paediatric Intensive Care Unit ward for Packed Cell Volume was 201 and Fresh Frozen Plasma was 300 followed by emergency ward for Platelet Rich Plasma. About 197 (6.45\%) requistions forms lacked the details of requesting department, while some even reveal multiple demands.

Conclusions: Packed Cell Volume of A positive blood group being the predominant blood component requested from Neonatal Intensive Care Unit/Pediatrics Intensive Care Unit ward at the institute making most requests. Finally, these results could be useful for estimating the requirements for our newly establish blood bank to meet the demand in future.

Keywords: blood component; Packed Cell Volume; transfusion units.

\section{INTRODUCTION}

Blood is a specialized bodily fluid that delivers necessary substances to the body's cells, such as nutrients and oxygen, transports waste products away from these same cells. ${ }^{1}$ Blood components as packed red blood cell, Fresh Frozen Plasma(FFP), cryoprecipitate, platelet transfusion have become vital and life saving procedures of patient management in modern medicine. ${ }^{2}$ Blood component separation facility began from $21^{\text {st }}$ April 2013 at the new blood bank complex at BPKIHS.
With the supply of blood components being finite with high rate of inappropriate use around the world, there is a need to monitor and regulate these services. Hence, regular audit of blood and its component usage is essential to access the blood utilization pattern and set

Correspondence: Dr Santosh Upadhyaya Kafle, Departmen of Pathology, Birat Medical College and Teaching Hospital, Morang, Nepal. Email: brsantoshkafle@gmail.com, Phone:+977-9852028480. 
ideal policies in all blood using specialties. ${ }^{3}$

Our study was conducted to identify blood component utilization pattern in the institute and to know about the different blood components demand for future preparedness.

\section{METHODS}

This retrospective study was conducted at B.P Koirala Institute of Health Sciences, Dharan, Nepal. It was done for blood component dispatched from $21^{\text {st }}$ April 2013-12 ${ }^{\text {th }}$ February, 2014. For this study, a retrospective analysis of blood component requisitions in all patients from various clinical departments were reviewed regarding number of specific blood component units requested, the speciality department prescribing it, blood group and socio-demographic profile. After analysis and review of the aforementioned data, suggestion was generated with the help of the staff of blood bank component separation section and hospital to improve the utilization of blood and blood components. For which, simple descriptive statistical analysis was done for all the collected data.

\section{RESULTS}

The present study was conducted upon 3054 transfusion units for different blood components dispatched over a period from $21^{\text {st }}$ April-12 $2^{\text {th }}$ February, 2014. Out of total 3054 transfusion units dispatched for different blood components, 1552 were males, 1498 females and 4 patients were with no any gender identification details. The distribution of blood components unit depending upon different ages is shown below in Table 1 .

\begin{tabular}{|lll|}
\hline $\begin{array}{l}\text { Table 1. Distribution of blood component units } \\
\text { depending upon age. }\end{array}$ & \\
\hline Age Range & $\begin{array}{l}\text { Frequency of blood } \\
\text { component units }\end{array}$ & \\
$<11$ months & 258 & \\
$1-9$ years & 75 \\
$10-19$ years & 170 \\
$20-29$ years & 408 \\
$30-39$ years & 226 \\
$40-49$ years & 178 \\
$50-59$ years & 197 \\
$60-69$ years & 158 \\
$70-79$ years & 91 \\
$80-89$ years & 47 \\
$90-99$ years & 6 \\
\hline
\end{tabular}

dispatched, 1722 were (Packed Cell Volume) PCV, 808 were PRP, 523 were Fresh Frozen Plasma (FFP) and 1 Cryoprecipitate (Figure1). There was single to multiple blood component units requisition in different requests from different clinical departments.

\section{Blood Component Units Despatched}

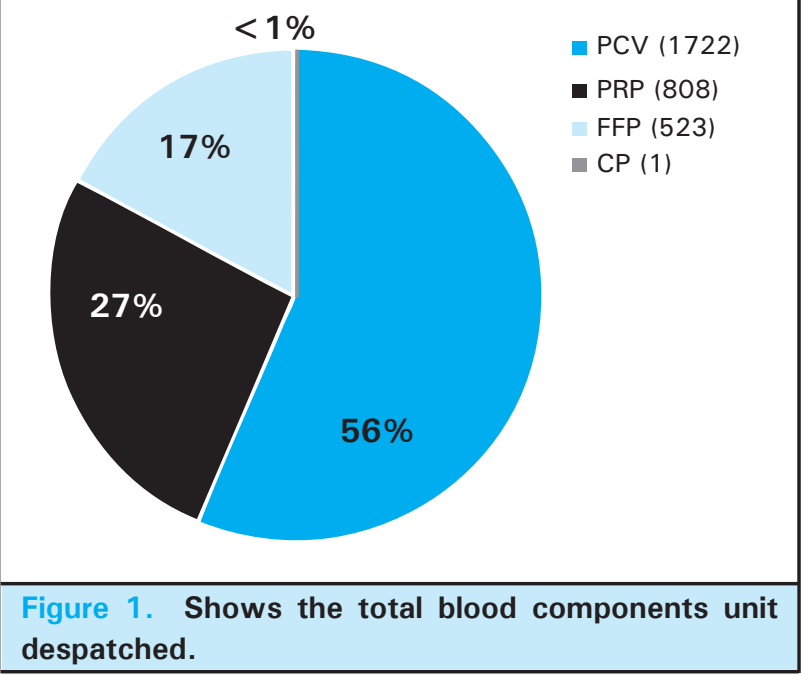

Out of the total PCV (1722) units dispatched, 343 $(33 \%)$ was of A positive blood group followed by $330(31 \%)$ of O positive, $256(24 \%)$ of B positive, $116(11 \%)$ of $A B$ positive and $10(1 \%)$ collectively of A negative, $B$ negative and $O$ negative blood group. Likewise, the total PRP (808) units dispatched, 158 $(63 \%)$ was of A positive blood group followed by 147 (34\%) of O positive, 80 (18\%) of B positive, 52 (12\%) of $A B$ positive and $1(<1 \%)$ of $A$ negative blood group. Similarly, the total FFP (523) units dispatched, 107 $(33 \%)$ was of A positive blood group followed by 97 (30\%) of O positive, $73(23 \%)$ of B positive, 39 (12\%) of $A B$ positive and $5(2 \%)$ collectively of $B$ negative and $\mathrm{O}$ negative blood group.

The different clinical departments requesting the most blood components was Neonatal and Pediatric ICU (NICU/PICU) wards of 300 requests for FFP, 201 for PCV and Emergency (ER) ward of 116 PRP (Figure 2-4). 

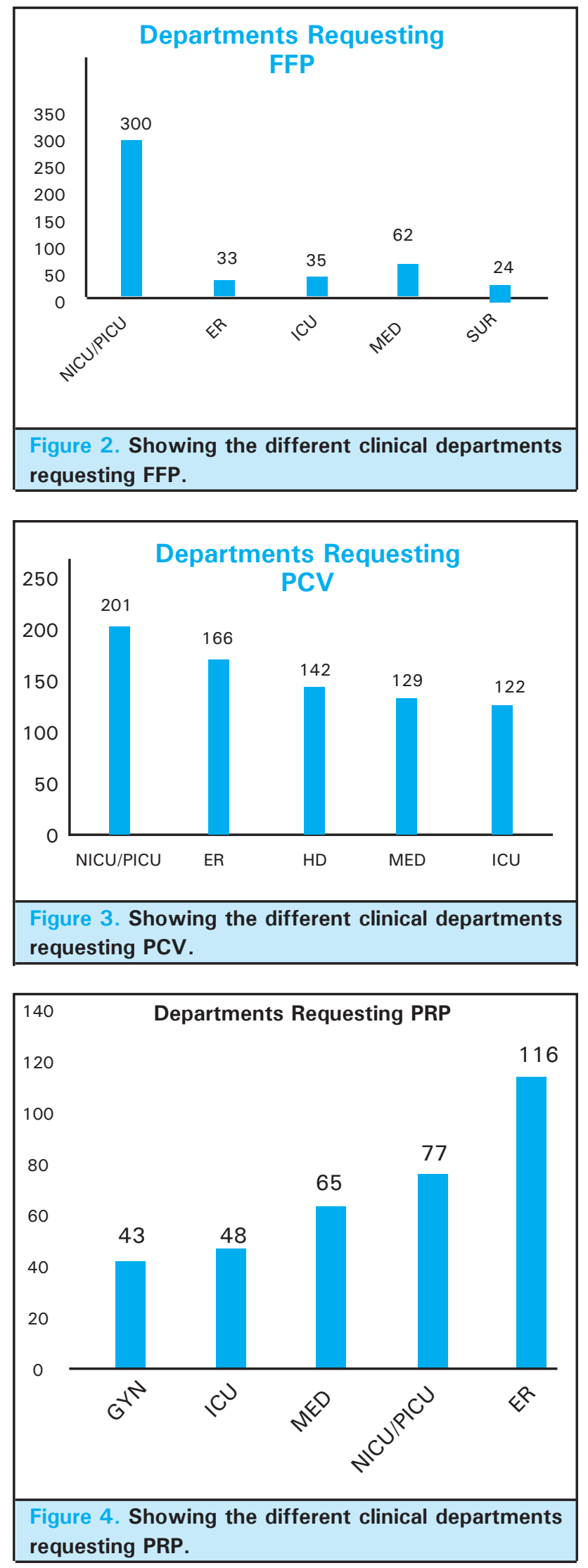

\section{DISCUSSION}

This retrospective study conducted at B.P Koirala Institute of Health Sciences, Dharan, Nepal describes the patterns of different blood component units distribution according to the specific requists received from the respective clinical departments. According to which, a total of 3054 transfusion units for different blood components dispatched over a period from $21^{\text {st }}$ April-12 ${ }^{\text {th }}$ February, 2014 were recorded with 1552 as males, 1498 females and 4 patients were with no any gender identification details. Among which the age groups lying between 20-29 years were in the highest number, requiring with 408 blood component units. Some of them even had multiple blood component units.

Similar kind of retrospective study conducted by Venkatachalapathy TS and Das S concluded upon 1694 episodes of transfusion units for different blood components revealing 208 of males and 588 as females, which is quiet different than of ours study record of male being in more number than of females. Not only this but they even concluded the importance of periodic review of the blood and its component usage pattern in hospital. According to the study, the judicious implementation of guidelines for use of various blood components may help to decrease the inappropriate use of blood and its component. In addition such study will ensure the availability of the blood and its component to needy patients and save many patients from the transfusion related reactions as well. ${ }^{4}$

Likewise, our study also demonstrates the very initial status and figures of the newly established blood component collection, storage and dispatching centers. In addition, being confined to the tertiary care medical college and teaching hospital with almost all existing departments of medical education, the future demand and use of such blood and its components would increase in number.

Among 3054 total blood component units dispatched, 1722 were PCV, 808 were PRP, 523 were FFP and 1 Cryoprecipitate (Figure 2). There was single to multiple blood component units requisition in different requests from various clinical departments. The different clinical departments requesting the most blood components was Neonatal and Pediatric ICU (NICU/PICU) wards of 300 requests for FFP followed by 62 units from Internal Medicine ward, 35 units from the ICU, and of 33 and 24 us nit from Emergency and General Surgery wards respectively (Figure 6).

Similarly, the NICU/PICU wards again has the highest PCV blood components requisite of 201 units, followed by Emergency wards, Hemodialysis wards, Internal 
Medicine wards and ICU of 166, 142, 129 and 122 units of PCV respectively (Figure 7). Regarding the most requesting clinical departments for the blood components of PRP units, the NICU/PICU ward again has the highest units of 72 , followed by the other clinical departments. Of which, the Internal Medicine, ICU and Gyanecology wards shared 65, 48 and 43 units of PRP respectively (Fig. 8). These types of blood component unit distribution data shown in the study of Venkatachalapathy TS and Das S4 were 912 for PCV, 306 for PRP and 331 for FFP among the total 1694 episodes of transfusion units. These sorts of internal audit ultimately becomes a useful tool in making the different blood components transfusion related strategy and policies for future preparedness and action. In another way, we can also predict or estimate from such result about the most requesting department for the blood components unit for exploring the disease pattern as well.

In our study, we also analyzed the data for individual blood group for the dispatched blood components. Out of the total PCV of 1722 units dispatched, 343 (33\%) was of A positive blood group followed by 330 (31\%) of O positive, $256(24 \%)$ of B positive, $116(11 \%)$ of $A B$ positive and $10(1 \%)$ collectively of $A$ negative, $B$ negative and $O$ negative blood group respectively (Figure 3). Similarly, for the total PRP of 808 units dispatched, $158(63 \%)$ was of A positive blood group followed by $147(34 \%)$ of $O$ positive, $80(18 \%)$ of $B$ positive, $52(12 \%)$ of $A B$ positive and $1(<1 \%)$ of $A$ negative blood group respectively (Figure 4).

Likewise, for the total FFP of 553 units dispatched, 107 $(33 \%)$ was of $A$ positive blood group followed by 97 (30\%) of O positive, 73 (23\%) of B positive, 39 (12\%) of $A B$ positive and $5(2 \%)$ collectively of $B$ negative and $\mathrm{O}$ negative blood group respectively (Figure 5 ).

This sort of the internal audit data not only helps in tracing out the exact use and prepare for future demand of the individual blood components, but also can play a vital function for quality control mechanism even. These facts in detail have been prescribed and proved in the studies done by McCullough $\mathrm{J}$ and Steeper TA et al and Silver $\mathrm{H}$ and Tahhan $\mathrm{HR}$ et al, ${ }^{5,6}$ where the internal audits form an integral part of the quality control programme in any blood bank, like in any other organization. Studies done by Brandia $\mathrm{K}$ et al and Joshi $\mathrm{GP}$ et $\mathrm{al}^{7,8}$ has the common conclusion, stating about the easy and indiscriminate use of blood components is on a high demand for its easy availability of sophisticated blood banking services. Thus, the blood bank should be able to update and fulfill the demand for this life saving product. Moreover, it should be able to evaluate and access the existing systems and trends of ordering the blood units.
Considering these facts of the blood and its component being one of the life saving product, the blood bank should always try to maintain the replacing blood units after delivery or dispatching of each blood units. So that the blood units storing in the blood bank is always maintained for each and every demand of it.

Moreover, the tendency of replacing the dispatched blood units in the blood bank should be increased, so that every demand and requisites for blood units would be fulfilled to overcome any life threatening situations demanding the use of blood and its components. Likewise our study showed that, some of the requisition forms demanding such blood component units even lacked the necessary and important details. This was one of the unwanted findings we came across our study. In another way, we can interpret that the necessary details about the patients identification regarding the full name, age, sex, proper address, blood group (if already known), total blood components units required, clinical or working diagnosis if possible etc. should be clearly mentioned in every such blood component units requisition form.

Finally, we would achieve more favorable result if up gradation of blood component storage and other facilities are considered at the blood bank which requires dealing with more inventories. Likewise, a software based system for monitoring stock and predicting the utilization is mandatory. Generating a list of donors who can be used at the time when blood shortage and to avoid unavailability would be a great step for regular supply of such blood units. In addition, continual education programs to improve the performance of any related staffs would prove fruitful exercise to increase the appropriate use of whole blood and its component.

\section{CONCLUSIONS}

The most distributed blood component units was PCV followed by PRP, FFP and cryoprecipitate. A positive blood unit was the predominant requested blood units among all blood component units. The NICU/PICU ward demanded the most FFP and PCV blood components in the institute followed by the Emergency department demanding the most PRP blood components unit. Some of the blood component demand requisition forms lacked the essential details even. Finally, these results could be useful for estimating and planning the requirements for our newly established blood component units separation service to meet the demand in future.

\section{ACKNOWLEDGEMENTS}

Authors would like to acknowledge all the staffs of the 
blood bank component separation service unit headed by Mr. Jitendra Sharma of B.P Koirala Institute of Health Sciences, Dharan, Nepal.

\section{Conflict of Interest: None.}

\section{REFERENCES}

1. Singhal M, Patel M, Kapoor Devesh et al. A research analysis on blood component usage and wastage in blood bank and blood component center. J Physiol. Pathophysiol. 2013;4(2):23-28. [Full Text]

2. Abdul-Rahman IS. Renal disease in hematological malignancies. Hong Kong J. Nephrol. 2009;13(1):5-18. [피l Text]

3. Vishwanathan C, Jain R, Kamath M. Blood utilization review in a tertiary care hospital. Indian J Haematol Blood Transf. 1999;17:26-31. [Full Text]

4. Venkatachalapathy TS, Das S. A Prospective Audit of Blood Transfusion Requests in Rl Jalappa Hospital and Research Centre for Blood and Blood Components. J Blood Lymph. 2012;2:106. [Full Text]
5. McCullough J, Steeper TA, Connelly DP, Jackson B, Huntington S, et al. Platelet utilization in a university hospital. JAMA. 1988 April 22-29;259(16):2414-8. [PubMed]

6. Silver H, Tahhan HR, Anderson J, Lachman M. A non-computer-dependent prospective review of blood and blood component utilization. Transfusion. 1992;32(3):260-5. [PubMed]

7. Brandis K, Richards B, Ghent A, Weinstein S. A strategy to reduce inappropriate red blood cell transfusion. Med J Aust. 1994;160(11):721-2. [․ㅏbMed]

8. Joshi GP, Landers DF. Audit in transfusion practice. J Eval Clin Pract. 1998;4(2):141-6. [PubMed] 